\title{
The attractiveness of public-private partnership for road projects in India
}

\author{
Mohammed Shakil Malek ${ }^{a^{*}}$ and Laxmansinh Zala ${ }^{b}$
}

${ }^{a} F$. D. (Mubin) Institute of Engineering and Technology, India

${ }^{b}$ Birla Vishvakarma Mahavidyalaya, India

\begin{tabular}{l}
\hline C H R O N I C L E \\
\hline Article history: \\
Received: March 20, 2021 \\
Received in revised format: July \\
28,2021 \\
Accepted: October 6, 2021 \\
Available online: \\
October 6, 2021 \\
\hline Keywords: \\
Attractive Factors \\
Effective Index \\
India \\
Public-Private Partnership (PPP) \\
Roads
\end{tabular}

\section{Introduction}

The improvement of essential infrastructure is a basic need for matching the development prerequisites of a nation. Infrastructure financing requirements being a greater challenge can't be matched by the government individually and consequently. The case for private-sector support is strongly needed to meet this challenge (Gunjeet Kaur et al., 2009). PPP (Public-Private Partnership) is recommended for the capability to resolve the deficit in government finance, and for utilizing the capacity of the private sector to construct and maintain infrastructure assets (Akintoye et al. 2016). Because of these advantages, many nations considered PPPs to be important and hence the preferred way for providing infrastructure services (Klijn \& Teisman, 2000). These PPP initiative implementations have progressed by concentrating on different dimensions of research. The success of PPPs has shifted the research investigation from how to run to how to popularize the use of PPP (Cui et al. 2018). Because of the decrease in public spending in the provision of infrastructure services, early implementation of PPPs marked the reason for attracting private investment (Crosslin 1991). It has motivated researchers to build financial models and facilitate them to comprehend the financial feasibility and value for money (VFM) of PPPs (Malek \& Gundaliya 2020). Later on, studies have been found that the united members of PPPs have an opposing concern (Malek et al., 2020). It was dealt with through the study of organizational forms and the particular emphasis on the procurement stage, thereby opening the application of theories in the study of PPP procurement (Zhang \& Kumaraswamy, 2001). Observation of the suitability and appropriateness of involving PPP and the conditions for which a successful PPP plan is set out was recently an aspect of the sound PPP decision. Cui et al. (2018) have reported that internal project variables such as their financial * Corresponding author.

E-mail address: shakil250715@yahoo.co.in (M. S. Malek)

C 2022 Growing Science Ltd. All rights reserved. doi: $10.5267 / j . j p m .2021 .10 .001$ 
feasibility, VFM, and stakeholder satisfaction influence the appropriateness of the PPP as the preferred path. In certain infrastructure projects, support of the universal principle that PPPs boost the quality of infrastructure services has been challenged. One of the reasons is that the sectoral characteristics are confirmed (Flyvbjerg et al. 2004). Eadie et al. (2013), for example, stated that in the UK PPP is suitable for the implementation of health and transport projects. Henjewele et al. (2014) stressed that, due to less delay in the UK's transport sector, the output of the PPP projects in the transport sector exceeds the health sector. However, Rajan et al. (2014) have challenged the PPP's capacity to reduce delay and suggested that PPPs in the Indian transport sector have proved to be ineffective.

India ranks among the countries having the largest road networks in the world, approximately a total of 5.5 million kilometres. The Government of India (GOI) has realized the need for huge investments in the sector to fuel economic growth. The Government of India's Vision 2021 identified transport infrastructure as a foremost restraint to the financial development and assessed the capital funding needs to be around 82 billion USD on highway improvements by 2022 and 1.4 trillion by 2025. For the development of such a large road sector, GOI requires a huge amount of money. The problem for GOI is to arrange the funding for such massive investments. During the last five years in India, the highway construction rate increased almost $250 \%$ (12 km/day in 2014-15 to $30 \mathrm{~km}$ /day in 2018-19). The private participation required in accomplishing the expected road development is about $56 \%$ (Chaturvedi, 2009). The private-sector involvement was only 5\% in the tenth fiveyear plan and was estimated to rise to $34 \%$ in the eleventh plan and $40 \%$ in the twelfth plan (Malek \& Akalkotkar 2016). But this trend could not be supported and it eased back to 5.6\% of GDP in 2013-2017 (Hans, 2017). This decrease in infrastructure investment by private companies in recent years has moderately been counterbalanced by the financial improvement. Due to the worldwide financial meltdown in 2008, the number of projects reduced to 58 in 2010 (Malek et al., 2020). Specifically, the objectives of the paper are to recognize and analyze the attractive factors affecting the attractiveness of PPP in Indian road projects.

\section{Background of attractive factors for PPP}

Several previous authors have been addressing the beneficial aspects of PPP, and this segment looks concisely at these factors. Why are governments around the world adopting PPP approaches to provide their public services and facilities? The public services and infrastructure, needs, and facilities have been important to the public. These infrastructure and facilities would pose a burden on the financial status of the state to provide them with the use of the Government fund. Therefore, it was the best solution for the public to have what they wanted to provide without the Government having to pay, and business prospects for the private-sector (Cheung et al., 2010). PPP has expanded the experience of developed countries, including the UK, Australia, the United States to emerging countries, including Brazil, China, Ghana, and India (Li et al. 2005a; World Bank Group 2016). The root of PPPs comes from the private funding program in the UK. To overcome the limitations the cash-loaded public sector selected for the PPP method. Most of the UK's PPP projects are financed by the private sector (Li et al., 2005b; Hodge \& Greve 2010). Public borrowing by the restriction on government shortage and total public sector debt is limited by governments, particularly for developing nations (Li et al., 2005a; Akintoye et al., 2016). Besides, the assets and facilities of the public sector are far from the requisite level. PPP offers an opportunity to meet rising infrastructure demand and supply. PPPs generate investment capital and decrease the need for public funds through creative project funding. Also, the debt portion is improved from the project's assured revenues (DEA, 2015). The financing of projects is expected to include foreign experts when funding is coming from international banks. It is observed that PPPs provide integration benefits in various forms concerning the provision of goods and facilities (HMT, 2012). The tasks like planning, funding, development, and operations are finer performed by the private sector. Compact and impractical projects that would or else not be executed can also be offered in the PPP module as a solo project, which is regarded to be granted the advantages of economies of scope and scale (Eaton et al., 2006; Hodge \& Greve, 2010). Therefore, PPPs are seen as allowing the public sector to furnish consolidated output on assets and services by reducing the obstructions that exist in conventional delivery methods. When more projects are financed by mode of project funding, the public sector has relieved themselves to finance infrastructure investment. The private sector spends required finance and redeems together with returns on investment using toll collection from a user (Bain, 2009; Cheung et al., 2010). PPP offers a reduction in various ways. The attractiveness of PPPs is important. From a competitive and productive point of view, an implacable review of the private sector would encourage capping the final cost of operation down to some planned rates, as defined by the PPP concession agreement (DEA 2015). Also, competitive tendering permits the government to control the final cost of the entire contract. PPP is therefore subject to cost overrun checks and reduced overall project cost due to its business focus and autonomy which enables creative asset and service delivery methods to be quickly selected (Eaton et al., 2006; Hodge \& Greve 2010; DEA 2015). PPPs are therefore a solution to time overruns that have overwhelmed conventional methods. This is because of the opportunity to gain profits by completing the project timely. For example, it took six days for the PPPs to complete one km of roads and it took 16 days for the EPC (Engineering Procurement and Construction) to complete the equal one $\mathrm{km}$ of road in the Indian road sector (Thillai Rajan \& Deep 2019). When procuring projects using PPP, the client must know to pursue an approach to scale the desired results rather than precise descriptions of the properties required for the project (HMT 2012). As an outcome, the private sector's ability to produce goods and services which meet the requirements of the project is very challenging. The use of materials, equipment, and other resources to achieve performance and quality is also leading to the buildability of the project (Ferguson \& Takane, 1989). This makes it easier to manage the project with the grouping of work breakdown like design, development, operation, and maintenance (Eaton et 
al., 2006). PPPs have also channeled the transfer of international technology into the local enterprise in the proximity to the project through a memorandum of understanding and joint ventures with local players using a win-win model (Li et al., 2005a). In such a case, the government may also choose to free themselves using risk transfer associated with supplying the project facilities. This incorporated the responsibility to execute within stipulated time and budget. The public-sector defines risk allotment in advance to private-sector bidding and anticipates benefit for the transferred risks (Akintoye et al., 2016). The private-sector can finish the project on time, through the accurate risk allocation and freedom given by the PPP. This will encourage the private sector to speed up the entire project development cycle by supplying the private sector with the latest, productive resources and technical skills. It is known that PPP can condense government administration costs allied to service delivery (Cheung et al., 2010). This is because a project monitoring unit can be introduced by the government to play an easy role in overseeing project results (Dolla \& Laishram, 2018). Also, PPPs impact local development by offering various secondary resources and economic incentives ( $\mathrm{Li}$ et al., 2005a). Factors identified from the literature, which were affecting the attractiveness of PPP for road projects, are summarized in Table 1.

\section{Table 1}

Citation of Attractive factors in PPP road projects by different Authors

\begin{tabular}{|c|c|c|c|c|c|c|c|c|c|c|}
\hline Factors & (A) & (B) & (C) & (D) & (E) & (F) & $(\mathrm{G})$ & $(\mathrm{H})$ & (I) & $(\mathrm{J})$ \\
\hline Resolve Government's financial constraints & * & & * & & $*$ & * & * & * & \# & \# \\
\hline Enhances government integrated solution capacity & * & $*$ & \# & * & $*$ & $*$ & & $*$ & $*$ & \\
\hline Reduces government fund tied up in capital investment & \# & & \# & & $*$ & $*$ & $*$ & \# & \# & \\
\hline Cap service cost & \# & $*$ & & & $\#$ & $*$ & * & \# & $*$ & \\
\hline Private sector's skills and experience & * & \# & \# & & * & * & * & * & $*$ & \\
\hline Minimize total project cost & \# & & & & & $*$ & & $*$ & & \\
\hline Project cost and time control & \# & $*$ & * & & & * & * & \# & $*$ & $*$ \\
\hline Risk transfer to private party & * & & \# & & $*$ & $*$ & $*$ & \# & $*$ & $*$ \\
\hline Reduces government administration cost & * & & & & $\#$ & $*$ & * & $*$ & & \\
\hline Promote local economic development & * & & & & $\#$ & \# & & $*$ & & $*$ \\
\hline Improve buildability & * & & & & $\#$ & $*$ & $*$ & * & \# & \\
\hline Improve maintainability & * & & & & & $*$ & & * & \# & \\
\hline Enhances technology transfer to the local enterprise & * & * & & & & $*$ & $*$ & * & $*$ & \\
\hline Non-recourse financing & * & & * & & $*$ & \# & * & * & \# & \\
\hline Accelerate project development & \# & $*$ & & & $*$ & $*$ & & $*$ & $*$ & \\
\hline
\end{tabular}

Accelerate project development

* Represents research has indicated with analogous terms; \# represents research has evaluated in a vast sense. Reference: (A) Li et al., 2005; (B)

Eaton et al., 2006; (C)Bain, 2009; (D)DEA, 2015; (E)Hodge and Greve 2010; (F)Cheung et al., 2010; (G)HMT, 2012; (H)Robert et al., 2014;

(I)DEA, 2015; (J)Akintoye et al., 2016.

PPP road projects are complex and require a contribution from various parties of distinct competence. The literature review indicates that the previous studies focused on the requirement of infrastructure development using the PPP approach and attempted to take maximum possible factors that are accountable for the successful completion of PPP projects. The Indian road sector required a high amount of investment, so it is desirable to pay more attention to the effectiveness of attractive factors for the successful completion of projects. The problem to be investigated is the effectiveness of all these factors concerning the perceptions of respondents in PPP road projects.

\section{Methodology}

The research is exploratory. The questionnaire survey is used to accumulate the data as it is a basic and effective tool for quantitative data analysis. This approach is mostly used and well recognized in social science and management research. Various researchers adopted this approach in the field of construction management (Cheung et al. 2010; Dolla \& Laishram 2019; Hwang et al. 2013). Wider geographic coverage, reduction in bias, greater anonymity, and low cost are some of the advantages of the questionnaire approach (Malek \& Gundaliya 2020, 2020a).

\subsection{Questionnaire survey}

The questionnaire which was carried out in this research was contained in two parts. The first part comprises the general information of the respondents who participated in the survey. It contains experience, qualification, and organization. The second part comprised the attractive factors of PPP in the Indian road sector. The questionnaire which was employed out in this research was validated with the help of PPP experts, who are practitioners having sound knowledge and rich experience in the Indian PPP road sector. For validation six experts from the public sectors, eight from the private sector, and six from the researcher were selected. To increase the reliability of survey results all the respondents were selected from the top and higher middle-level personnel with rich experience in the respective field. These respondents were asked to indicate their level of understanding for all recognized factors based on a Likert five-point scale in which 5 is least important and 1 is most important.

\subsection{Sampling and Data collection}

The target respondents included all the personnel connected with the implementation of the PPP road project in India i.e., private-sector consisting of developers, contractors, consultants operating in India; public-sector and the researchers from the various reputed institutions of India. The respondents were selected based on their ample understanding of PPP and 
experience towards PPP road projects at various stages (Cheung et al.,2010). Snowball sampling is used as it is suitable for such type of research (Dolla \& Laishram 2019).

Amongst 500 sent questionnaires, 275 replied. Response ratio achieved 55 percent which is acceptable and good enough for such a type of a survey (Li et al., 2005a; Cheung et al., 2010; Dolla \& Laishram 2019). 43\% of respondents have more than 20 years of experience; $41 \%$ of respondents in between 11 to 20 years and $16 \%$ of respondents less than 10 years. $50 \%$ of respondents belong to the private sector and $26 \%$ belong to the public-sector while $24 \%$ are researchers. The reason for more of the respondents from the private sector is, in India public sectors are normally giving work to private sectors including design to completion of work under PPP.

\section{Data Analysis}

The data accumulated is required to test the reliability and validity of the survey tool, ranking of the attractive factors, testing of hypotheses to evaluate variances in the perception of various groups of respondents, and exploratory factor analysis of the attractive factor was also performed from the collected data. Initially, a reliability test was performed using Cronbach's alpha before a thorough analysis to check the reliability of the factors. The Cronbach's alpha value for this study is 0.767 which shows that factors are reliable measures for further analysis. The respondents were requested to rate the effectiveness of these selected attractive factors according to their experience and perception. Scaling from 'Not Effective' to 'Very Effective' was chosen to quantify the effectiveness of attractive factors. The effectiveness is presumed to be the combined result of the possibility and influence of the existence of that particular factor. Malek and Gundaliya (2020, 2020a) and Malek et al. (2021) used the index for calculating the effectiveness of each factor as below:

$$
\text { Effective Index (E. I. })=\frac{5 n_{5}+4 n_{4}+3 n_{3}+2 n_{2}+n_{1}}{5\left(n_{5}+n_{4}+n_{3}+n_{2}+n_{1}\right)}
$$

Where, $\mathrm{n}_{5}, \mathrm{n}_{4}, \mathrm{n}_{3}, \mathrm{n}_{2}$, and $\mathrm{n}_{1}$ represent no. of persons who responded who selected most effective to not effective in decreasing manner respectively. I.I. $\leq 0.50$ is considered as most effective, $0.5 \leq$ I.I. $\leq 0.7$ as very effective, $0.7 \leq$ I.I. $\leq 0.9$ as effective and $>0.9$ as not effective. To compare the mean criticality rating between different categories of respondents, Analysis of Variance (ANOVA) using an F-test was carried out (Mendenhall 1971; Levin et al. 2013). The hypothesis tested using one way ANOVA is:

The hypothesis $\left(\mathrm{H}_{0}\right)$ is, there is no noteworthy diversity in the opinion of public-sector, private-sector, and researchers for choosing attractive factors for the effectiveness of PPP road projects. In general ANOVA / F-test just figures out if there is any significant difference that lies between the means. When the F score is statistically significant, the Post-Hoc test (Tukey HSD) was performed (Kirkpatrick and Feeney 2001). This test at a time compares two means sets, to identify specifically, where the significant dissimilarity exists. Factor analysis (FA) is utilized for recognizing a comparatively less integer merging for factors that are then utilized to indicate interrelation between a set of numerous interrelated variables (Malek \& Gundaliya, 2020a). It is a method pertinent when there is a methodical relationship between a set of identified variables. It is also used to recognize a moderately small number of component groupings that can be utilized to examine connections amongst a set of numerous interrelated variables. Kaiser Meyer Olkin (KMO) and Bartlett test were conducted to measure the adequacy of sampling which ought to be more noteworthy than 0.5 for acceptable factor analysis to continue. The present study data has significant acceptability as its KMO value comes to 0.692 which is more than 0.5 . Bartlett's test is another sign of the quality of the relationship amongst variables. The value of $p$ for present data $(p=0.000)$ is less than 0.05 , of the significance level, demonstrating that factor analysis can be used with the data (Coakes 2005). The principal component analysis was embraced with the help of the Scree diagram and Kaiser's principles of eigenvalue more than 1 for the extraction of the factors (Malek \& Gundaliya, 2020a). The Scree diagram for attractive factors is mentioned in Fig. 1. For a better interpretation of results, the varimax rotation method is used. Four fundamental clustered factors were extracted and rated for $65.04 \%$ of the variance in feedback. Usually, SPSS omits the specific factors with less than one eigenvalue. In this study, not a single factor is dropped.

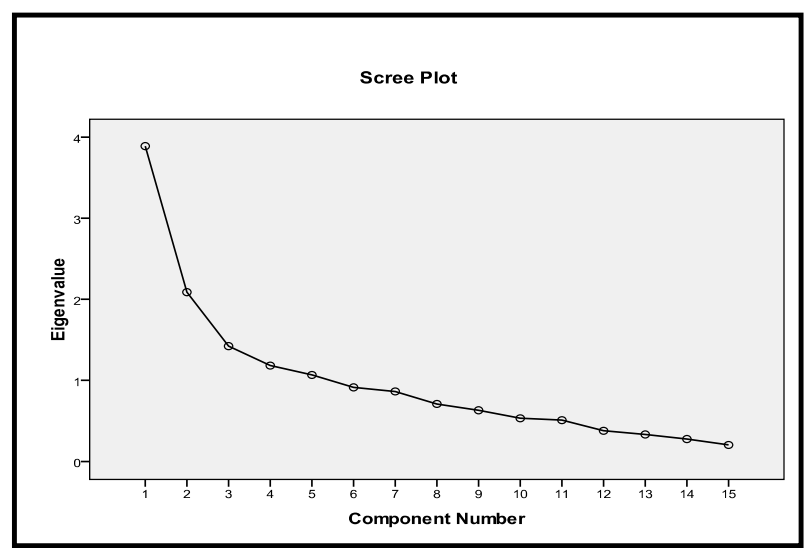

Fig. 1. Scree plot for Attractive factors 
All the factor loadings were greater than 0.5 in the present study. FA method may cluster all the factors without any elimination and elucidate the threshold variance as witnessed in various earlier studies (Malek \& Gundaliya, 2020). Factor loading differs from 0 to 1 . Upper values signify a better involvement of a factor to the component is an extent of the grade of involvement (Malek \& Gundaliya, 2020a). Also, a positive factor loading signifies a positive association between distinct factors and vice versa. The cumulative variance illuminated by the principal components extracted is more than the threshold of $60 \%$ for vigorous FA (Malek \& Gundaliya, 2020). The results are presented in Table II. The labeling of factors is idiosyncratic and theoretic to replicate the conceptual intent (Malek \& Gundaliya, 2020a).

\section{Findings and Discussion}

\subsection{Factor Analysis}

FA was used to analyze the collected data to investigate the alliance that may exist among the identified factors. These groupings can deliver precious assistance to the public sector for seeking improvement of the PPP approach, and to the private sector in the planning of the business case for specific projects ( $\mathrm{Li}$ et al. 2005).

Table 2

Grouping results after Rotated Component Matrix for attractive factors

\begin{tabular}{|c|c|c|c|c|}
\hline Label & Factor & Component 1 & Component 2 & Component 3 \\
\hline \multirow{6}{*}{$\begin{array}{l}\text { Efficiency of } \\
\text { Private Sector }\end{array}$} & Enhances technology transfer to the local enterprise & 0.826 & & \\
\hline & Private sector's skills and experience & 0.742 & & \\
\hline & Improve buildability & 0.696 & & \\
\hline & Promote local economic development & 0.661 & & \\
\hline & Improve maintainability & 0.655 & & \\
\hline & Accelerate project development & 0.475 & & \\
\hline \multirow{4}{*}{$\begin{array}{l}\text { Effective time } \\
\text { and cost } \\
\text { management }\end{array}$} & Reduces government fund tied up in capital investment & & 0.727 & \\
\hline & Risk transfer to private party & & 0.712 & \\
\hline & Reduces government administration cost & & 0.49 & \\
\hline & Project cost and time control & & 0.45 & \\
\hline \multirow{5}{*}{$\begin{array}{l}\text { Public sector's } \\
\text { economic benefit }\end{array}$} & Resolve Government's financial constraints & & & 0.618 \\
\hline & Enhances government integrated solution capacity & & & 0.568 \\
\hline & Minimize total project cost & & & 0.532 \\
\hline & Cap service cost & & & 0.463 \\
\hline & Non-recourse financing & & & 0.459 \\
\hline & Eignvalue & 3.890 & 2.088 & 1.422 \\
\hline & Percent of variance explained & 25.932 & 13.920 & 9.480 \\
\hline
\end{tabular}

Notes: Extraction Method: Principal Component Analysis; Rotation Method: Varimax with Kaiser Normalization; Rotation converged in 5 iterations.

\subsubsection{Efficiency of private sector}

As mentioned in Table 2, comprises six factors with factor loadings varying 0.475 to 0.826 , which are: enhances technology transfer to the local enterprise; private sector's skills and experience; improve buildability; promote local economic development; improve maintainability and accelerate project development. High loadings are stated to enhance technology transfer to the local enterprise (0.826) and the private sector's skills and experience (0.742). PPP provides the potential for both private and public sectors for innovation and creativity. When conditions are in a description form of the required result instead of detailed input definition, PPP would encourage creativity in delivering public infrastructure (Li et al., 2005b). This empowers the private-sector to be further inventive and evolve a distinctive strategy to required project delivery (Birnie 1999). PPP provides the possibilities for local players to acquire the technology and expertise of foreign players who are experts in implementing PPP projects. It also benefited in the financial improvement at the local governments as PPP generated more opportunities for business and jobs (Robert et al., 2014).

\subsubsection{Effective time and cost management}

It comprises four factors with factor loadings varying 0.450 to 0.727 , which are: reduces government funds tied up in capital investment; risk transfer to a private party; reduces government administration cost and project cost and time control. Higher loadings are given to reduce government funds tied up in capital investment $(0.727)$ and risk transfer to a private party (0.712). In the traditional method, either the public or private sector bears all risks related to the project, while PPP provides both private and public sectors opportunity for risk-sharing in delivering public infrastructure. PPP offers benefits of efficient risk management if it is assigned to a suitable party (Fourie \& Burger 2000). Therefore, it is essential for risk to be appropriately recognized and assigned to the party that has an enhanced improvement approach to control it. Besides, efficient risk management indicates the public sector acquiring a more consolidated technique to deliver the project.

When public projects are transferred to the private sectors, because of the private sector's effective and efficient tactic of implementing government projects, such administrative costs are decreased and regulated precisely. Because of the private sector's effective and efficient method for controlling and expending available funds, the government provides some funding 
support to them, and the private sector utilizes and manages it in a better way (Robert et al., 2014). GOI is also providing such funding under the scheme of VGF.

\subsubsection{Public sector's economic benefit}

It comprises five factors with factor loadings varying 0.459 to 0.618 , which are: resolve government's financial constraints; enhance government integrated solution capacity; minimize total project cost; cap service cost and non-recourse financing. Higher loading is given to resolve the government's financial constraints $(0.618)$ and enhances government integrated solution capacity $(0.568)$. The Private-sector is accountable for funding, designing, construction, operating, and maintenance. To better maintain the public infrastructure more technical and advanced approaches are adapted that curtails the cost of the PPP project and also tumbling final service cost.

\subsection{Ranking of attractive factors for suitability of PPP}

The attractiveness of PPP is attached with effectiveness given in the ranking of factors. The effective index was calculated and ranked for all categories of the respondent as well as combined for all. Table III indicates the perception of publicsector, private-sector, and researchers for attractive factors. It also represents the mean, Effectiveness Index (EI), and ranking for all attractive factors group-wise based on rating by the public sector, private sector, and researcher respondents.

Table 3

Group wise Mean Rank and E.I. of Attractive factors

\begin{tabular}{|c|c|c|c|c|c|c|c|c|c|c|c|c|c|c|}
\hline \multirow{2}{*}{ Factors } & \multicolumn{3}{|c|}{ Public Sector } & \multicolumn{3}{|c|}{ Private Sector } & \multicolumn{3}{|c|}{ Researcher } & \multicolumn{5}{|c|}{ Combined } \\
\hline & Mean & E.I. & Rank & Mean & E.I. & Rank & Mean & E.I. & Rank & Mean & E.I. & Rank & $\mathbf{F}$ & Sig. \\
\hline Resolve Government's financial constraints & 4.45 & 0.89 & 1 & 4.23 & 0.85 & 1 & 3.89 & 0.78 & 6 & 4.21 & 0.84 & 1 & 5.814 & $0.003^{\wedge}$ \\
\hline Enhances government integrated solution capacity & 3.26 & 0.65 & 12 & 3.45 & 0.69 & 6 & 3.15 & 0.63 & 12 & 3.33 & 0.67 & 10 & 1.440 & $0.239^{*}$ \\
\hline Reduces government fund tied up in capital investment & 4.08 & 0.82 & 3 & 3.5 & 0.7 & 4 & 4 & 0.8 & 3 & 3.77 & 0.75 & 3 & 7.972 & $0.000^{\wedge}$ \\
\hline Cap service cost & 2.95 & 0.59 & 13 & 2.61 & 0.52 & 13 & 3.29 & 0.66 & 11 & 2.86 & 0.57 & 12 & 10.926 & $0.000^{\wedge}$ \\
\hline Private sector's skills and experience & 3.41 & 0.68 & 10 & 3.34 & 0.67 & 7 & 4.37 & 0.87 & 1 & 3.6 & 0.72 & 7 & 16.239 & $0.000^{\wedge}$ \\
\hline Minimize total project cost & 2.48 & 0.5 & 15 & 2.45 & 0.49 & 15 & 3.32 & 0.66 & 10 & 2.66 & 0.53 & 15 & 9.706 & $0.000^{\wedge}$ \\
\hline Project cost and time control & 3.84 & 0.77 & 6 & 3.73 & 0.75 & 2 & 4.06 & 0.81 & 2 & 3.84 & 0.77 & 2 & 1.901 & $0.151^{*}$ \\
\hline Risk transfer to private party & 3.42 & 0.68 & 9 & 3.34 & 0.67 & 8 & 3.52 & 0.7 & 9 & 3.4 & 0.68 & 9 & 0.621 & $0.538^{*}$ \\
\hline Reduces government administration cost & 3.56 & 0.71 & 8 & 3.12 & 0.62 & 11 & 2.88 & 0.58 & 14 & 3.18 & 0.64 & 11 & 7.379 & $0.001^{\wedge}$ \\
\hline Promote local economic development & 4.22 & 0.84 & 2 & 3.23 & 0.65 & 10 & 3.62 & 0.72 & 8 & 3.58 & 0.72 & 8 & 16.245 & $0.000^{\wedge}$ \\
\hline Improve buildability & 4.05 & 0.81 & 4 & 3.26 & 0.65 & 9 & 3.91 & 0.78 & 5 & 3.62 & 0.72 & 6 & 14.810 & $0.000^{\wedge}$ \\
\hline Improve maintainability & 4 & 0.8 & 5 & 3.49 & 0.7 & 5 & 4 & 0.8 & 3 & 3.75 & 0.75 & 4 & 7.482 & $0.001^{\wedge}$ \\
\hline Enhances technology transfer to the local enterprise & 2.74 & 0.55 & 14 & 2.77 & 0.55 & 12 & 3.11 & 0.62 & 13 & 2.84 & 0.57 & 13 & 2.168 & $0.116^{*}$ \\
\hline Non-recourse financing & 3.36 & 0.67 & 11 & 2.5 & 0.5 & 14 & 2.71 & 0.54 & 15 & 2.78 & 0.56 & 14 & 12.658 & $0.000^{\wedge}$ \\
\hline Accelerate project development & 3.63 & 0.73 & 7 & 3.57 & 0.71 & 3 & 3.75 & 0.75 & 7 & 3.63 & 0.73 & 5 & 0.531 & $0.589^{*}$ \\
\hline
\end{tabular}

Note: * - indicates that null hypothesis is accepted; $\wedge$ - indicates that null hypothesis is rejected and indicates difference in perceptions of stakeholders

For the 15 attractive factors, the $E I$ rating varies from 0.84 (resolve government's financial constraints) down to 0.53 (minimize total project cost). According to $E I$, no factor came under the most effective $(>0.9)$ and not effective $(\leq 0.50)$ classifications. This might be expected because of the common tendency for respondents to maintain a strategic distance from a prejudiced perspective, then to the straight-out nonappearance of any Most Effective and Least Effective factors. Their scoring non appearance essentially proposes that the Likert five-point scale was most likely endeavoring to gauge contrasts in perception that were excessively unpretentious at the zeniths, and does not negate the differentiations that were found (Li, 2005a,b,c).

\subsubsection{Very Effective attractive factors $(0.7<E I \leq 0.9)$}

Eight factors are identified as very effective factors affecting the attractiveness of PPP. The first very effective factor for the selection of PPP is its results in relieving constraints on the government budget (EI 0.84). In most developing countries, governments are facing a common issue of funding for infrastructure projects. To reduce the burden on the government budget, due to available confined finance, developing countries are motivated to implement PPP. It allows the government to conduct finance to further essential sectors for boosting the economy (Robert et al., 2014). Financial excuses are often the primary attractive factors for governments to adopt PPP. This factor is considered an important factor globally as it deals with government funds to fulfill competing needs (Cheung et al., 2010). Therefore, it is obvious that respondents have rated this attractive factor on the Very Effective side.

Project cost and time control (EI 0.77) get the second rank. Respondents consider other advantages of selecting PPP instead of only financial constraints. PPP offers the freedom to both the public and private sector to adopt an innovative approach which contributes to time reduction by expediting project development and by evading time and cost overrun in delivery of the project ( $\mathrm{Li}$ et al., 2005c). PPPs are used to save cost and time in conveying projects but many Indian road projects are affected by time and cost overrun in implementation. Ultimately it affects the country's economy. This may be the reason for getting the effectiveness of this factor. 
The other effective factors identified as improve maintainability (EI 0.75) and improve buildability (EI 0.72). Respondents suggested that the private-sector might enhance the maintainability of the built asset. In the context of life cycle integration, this anticipation is more grounded on services and assets that the private sector is anticipated to think through the design phase. Respondents suggested that actual PPPs could upgrade the capability to build services and assets. But, this is more sort of a hypothetical desire instead of a realistic observation. As it is a general tendency that the public sector is not that much aware to establish the required technologies. So it is obvious to anticipate that the private sector will do a little better than the existing one. This needs a deep understanding and updates about what is a global phenomenon, and the private sector has that capability.

The last two very effective attractive factors are the private sector's skills and experience (EI 0.72) and promote local economic development (EI 0.72). The private sector's skill and experience has been identified as an important benefit that can be brought by the private sector to public services and can provide at least costs and high competitiveness of the private sector. Any cost-effective technique acquired by the private sector would result in reducing cost and increasing profit (Hwang et al., 2013). It has been proven that through PPP, the government can generally enjoy services with better quality as PPP motivates the private sectors to be creative and innovative in project delivery.

Efficiency can be anticipated from the project when the private party, who has immense knowledge in related projects and the finance and the practical competence required for such projects, brings the project with the anticipated output stipulations within stipulated time and budget, which is an eye-catching factor for governments to opt PPP. For ensuring more value for money from the project, the private party incorporates all project phases in a single management structure which includes estimate, development, cost control, resource allotment, documentation, etc. (Almarri K., 2017).

The factor, benefit to local economic development, is identified by government policy and is hardly related to a discrete project. Also, it is difficult to measure precise advantages secured over the majority of the criterion used to describe financial improvement. However, it shows that in PPP public and private sectors are aware of the requirement for their projects to exhibit substantial financial benefits to the areas where they are located ( $\mathrm{Li}$ et al., 2005c).

\subsubsection{Effective attractive factors $(0.5 \leq E I \leq 0.7)$}

There are a total of seven factors identified in this segment. Risk transfer to a private party (EI 0.68) comes first in this segment. PPP allows risk to be divided among both public and private sectors. The private-sector is recognized for its capability to control risk using proficient asset attainment and facility deliverance (Robert et al., 2014). The factor indicates that the risk profile of the private sector could be enhanced by the PPP method. This is possibly due to the private sector being clear regarding the risks that were shifted to them and can be better ready for dealing with these risks (Hwang et al., 2013). For the government, risk transfer to the private party mitigates the complexity of undertaking big projects. Essential projects are occasionally overdue as the government cannot cultivate them systematically and could run into major risks which results in time and cost overrun of the deliverance of the facilities to the end-users. In this context by accepting the responsibility of developing the project based on specifications and by utilizing the needed financial support without revealing the government to any liabilities, the private party plays the biggest role (Almarri K., 2017). Risk transfer to the private party has demonstrated that Indian respondents robustly anticipated that risk transfer is not the most important attractive factor for PPP road projects.

Understanding such a response, requires an accurate perception of the sector, a variety of existing risks, and the risk allotment exercise. The private sector carries business risk and technology risk while remaining all related to the public sector. The other effective factors are enhancing government integrated solution capacity (EI 0.67), reducing government administration cost (EI 0.64), cap service cost (EI 0.57), and enhancing technology transfer to local enterprise (EI 0.57). Private sector participation in PPP has been supported to conquer the constraint of a traditional method. For the expansion of project scope integrated solutions are usually required. In the road sector, the key concern is associated with the allocation of services like design, build, operate and transfer to a sole private concessionaire. The reactions unavoidably found the reality that incorporated outputs are favorable only on a case by case basis. In the PPP approach to achieve the purpose to conquer the restrictions of the conventional method, private sector involvement is essential. This finding indicates that using the PPP approach, the scope of the project is able to reflect a broader perspective integrating various project components. This might allow the expansion of an incorporated result, like fastening different activities such as design, construction, financing, maintenance, etc. previously dealt with through various departments into a sole project, hence securing economies of scale (Debela, 2020).

Delivering government road projects using the traditional method indicates, the government disburses more on the administration of such projects. Usually, the government hires project managers and consultants for the supervision of the projects. Although once construction is over, for the maintenance of the new facility the government employs personnel. In this context opting for PPP transfers the cost of administrative work if any to the private sector and makes the public-sector free from the administrative liabilities (Robert et al. 2014). 
Capping the final service cost has been observed as a not that important attractive factor for acquiring PPP, as it ranked lower. This may be due to doubt on the capacity of the private-sector to cap the final service costs. In a developed country like the UK, it might have been expected that this factor would have ranked further low. Nevertheless, the ability of few projects to upgrade the technical proficiency in local regions should not be ignored, mainly in those where unemployment has high from the decline and obsolescence of antiquated mechanisms (Li et al., 2005c). In India, like the perception of risk to the private-sector, proficiency development using technology transfer to local enterprises has been a vital plan of PPP. This factor is positioned lower in the Indian road sector (ranked 13th). Still, this is essential and deserves a better response. However, so many technologies are so far used in different projects. Such transfer will occur barely if the local contractor is capable to set up the succeeding projects and manage them effectively by the transferred technology that is presently missing (Dolla and Laishram, 2019). This is perhaps as the instant results of this attractive factor could not be seen and thus the other attractive factors were comparatively more attractive.

The last two effective factors are non-recourse financing (EI 0.56) and minimize total project cost (EI 0.53). PPP projects are distinguished with non-recourse or inadequate resource project financing. Nevertheless, the prerequisite of non-recourse financing has been positioned as important but less compared to other attractive factors (ranked 14th). Indian PPP road projects experience obstacles in obtaining debt funding for such projects as there is an intensified anticipation of VGF for projects that are not economically viable. This may partially be because of the sectional essence where most of the time, the profits from the projects, tend to be extremely less to match the debt servicing requisite (Dolla and Laishram, 2019). This factor appears to be more important for the UK, maybe because the government is always looking for private finance, skills, management, experience, and manpower for emerging projects to attain competence (Almarri, 2017).

Despite the private-sector's effectiveness and efficiency (Malek et al. 2020), the bidding cost and funding of PPP projects cannot be underrated. On the contrary, the cost incurred in the tendering of PPP projects is too high (Malek and Gundaliya, 2020a). This fallout is a higher total project cost instead of it minimizing it. It is obvious for public and private sectors to identify this as an important factor for selecting PPP (Robert et al., 2014). The public sector did not select PPP for minimizing the project cost in the road sector, as it has been positioned as the last important attractive factor. This suggests that the public sector should recognize the cost reduction technique that can occur mainly when using PPP. This needs strong value for money scrutiny that is generally omitted in the Indian road sector (Dolla and Laishram, 2019).

\subsection{Difference in perception rating of different category of respondents}

To identify any substantial variance among the perception of public-sector, private-sector, and researchers one way ANOVA F - Test was carried out for each attractive factor (as mentioned in Table 3), as all factors are either very effective or effective. As represented in Table 3, only five out of fifteen factors were not recognized contradictorily by public-sector, private-sector, and researchers. These five factors are: enhances government integrated solution capacity; project cost and time control; risk transfer to a private party; enhances technology transfer to the local enterprise and accelerate project development. Post Hoc test (Tukey HSD) was carried out to see the differences among the groups for the remaining 10 factors. The details of the Post Hoc test are mentioned in Table 4.

Table 4

Post Hoc Test for Attractive factors with differences

\begin{tabular}{|c|c|c|c|c|}
\hline Attractive Factor & SECTOR (I) & SECTOR (J) & Mean Difference(I-J) & Sig. \\
\hline Resolve Government's financial constraints & Public & Researcher & $.55975^{*}$ & 0.002 \\
\hline \multirow[t]{2}{*}{ Reduces government fund tied up in capital investment } & Public & Private & $.57854^{*}$ & 0.001 \\
\hline & Researcher & Private & $.49635^{*}$ & 0.01 \\
\hline \multirow[t]{2}{*}{ Cap service cost } & Public & Private & $.33937^{*}$ & 0.05 \\
\hline & Researcher & Private & $.68647^{*}$ & 0 \\
\hline \multirow[t]{2}{*}{ Private sector's skills and experience } & Researcher & Public & $.9583^{*}$ & 0 \\
\hline & & Private & $1.0262^{*}$ & 0 \\
\hline \multirow[t]{2}{*}{ Minimize total project cost } & Researcher & Public & $.84362^{*}$ & 0.001 \\
\hline & & Private & $.87782^{*}$ & 0 \\
\hline \multirow[t]{2}{*}{ Reduces government administration cost } & Public & Private & $.43756^{*}$ & 0.015 \\
\hline & & Researcher & $.68472^{*}$ & 0.001 \\
\hline \multirow[t]{2}{*}{ Promote local economic development } & Public & Private & $.99290^{*}$ & 0 \\
\hline & & Researcher & $.60379^{*}$ & 0.01 \\
\hline \multirow[t]{2}{*}{ Improve buildability } & Public & Private & $.79932^{*}$ & 0 \\
\hline & Researcher & Private & $.65222^{*}$ & 0 \\
\hline \multirow[t]{2}{*}{ Improve maintainability } & Public & Private & $.51095^{*}$ & 0.004 \\
\hline & Researcher & Private & $.51095^{*}$ & 0.006 \\
\hline \multirow[t]{2}{*}{ Non-recourse financing } & Public & Private & $.85251^{*}$ & 0 \\
\hline & & Researcher & $.64847^{*}$ & 0.004 \\
\hline
\end{tabular}


The result shows that out of ten factors not a single factor was found contradictorily with all three groups. Public-sectors have given significantly higher weightage to reduce government administration cost and Promote local economic development compared to private-sectors and researchers. Both private-sectors and researchers give similar weightage to all these factors. Private-sector respondents consider Reduces government funds tied up in capital investment; Cap service cost; Improve buildability and Improve maintainability as lower significant factors compared to public-sector and researcher respondents. Researchers have given significantly lower weightage to resolve Government's financial constraints compared to both public as well as private-sector. Public and private-sectors have given significantly lower weightage to the Private sector's skills and experience and Minimize total project cost compared to researchers. Private-sector respondents consider Enhanced government integrated solution capacity and limited resources to public funding as higher significant factors compared to public-sector and researcher respondents. These factors are straight away connected to various advantages that the public sector achieves in PPP projects along with the private sector. This proposes researchers, public and private sectors are individual parties with various belief systems and every one of these participants has its explanations behind taking part in PPP. As a public sector, in general, is progressively worried about the social advantages and likewise, the private sector is more worried about business benefits the organization would attain out of the partnership.

\section{Conclusions and Implications}

A designed questionnaire survey was conducted to assess the perception of stakeholders from the public sector, privatesector, and researchers in the context of attractive factors in Indian road projects. All the factors were separated into three groups by FA and Rotated Matrix Analysis. The three groups are (1) Efficiency of the private sector, (2) Effective time and cost management, and (3) Public sector's economic benefit. These groupings represent the attractive attributes presented in the PPP method. Eight attractive factors were rectified as 'very effective' for influencing the attractiveness of PPP in Indian road projects. The top five attractive factors along with their $E I$ have resolved the government's financial constraints $(0.84)$; project cost and time control (0.77); reduces government funds tied up in capital investment $(0.75)$; improve maintainability $(0.75)$ and accelerated project development $(0.73)$. A satisfactory correlation between public-sector, private-sector, and researchers for attractive factor's effectiveness rating of Indian PPP road projects stakeholders derived. The ratings of the public representatives and the researchers were relatively low in comparison to the private sector. The findings are to be useful for all professionals, from both the public and private sector, who are either considering or currently involved with PPP projects considering the effectiveness of factors according to EI. The study is confined to PPP road projects. Future research can be extended to other sectors. The same questionnaire survey adopted for this research study could be repeated in another trans-national comparison.

\section{References}

Akintoye, A., Beck, M. \& Kumaraswamy, M.M. (2016). Public-Private Partnership: A Global review. London: Routledge. Almarri, K. (2017). Perceptions of the attractive factors for adopting public-private partnerships in the UAE. International Journal of Construction Management, 1-8. doi:10.1080/15623599.2017.1382082

Bain R. (2009). Review of Lessons from completed PPP projects financed by EIB. Luxembourg: European Investment Bank Birnie, J. (1999). Private finance initiative (PFI) - UK construction industry response. Journal of Construction Procurement $5(1), 5-14$.

Chaturvedi, D.K. (2009). Final report of BKC Committee on NHDP.

Cheung, E., Chan, A. P. C., \& Kajewski, S. (2010). Suitability of procuring large public works by PPP in Hong Kong. Engineering, Construction and Architectural Management, 17(3), 292-308. doi:10.1108/09699981011038088

Coakes, S. J. (2005). SPSS: Analysis without Anguish: Version 12.0 for Windows. Sydney, Australia: Willey \& sons Australia Ltd.

Crosslin, R. L. (1991). Decision-Support Methodology for Planning and Evaluating Public-Private Partnerships. Journal of Urban Planning and Development, 117(1), 15-31. doi:10.1061/(asce)0733-9488(1991)117:1(15)

Cui, C., Liu, Y., Hope, A., \& Wang, J. (2018). Review of studies on the public-private partnerships (PPP) for infrastructure projects. International Journal of Project Management, 36(5), 773-794. doi:10.1016/j.ijproman.2018.03.004

DEA. (2015). Position paper on the solid waste management sector in India. New Delhi, India: Department of Economic Affairs, Ministry of Finance, Government of India.

Debela, G. Y. (2020). Attractive factors of Public Private Partnership (PPP) for road projects in Ethiopia. Developing Country Studies, 10(2), 11-22. DOI: 10.7176/DCS/10-2-03

Dolla, T., \& Laishram, B. S. (2018). Procurement of low carbon municipal solid waste infrastructure in India through public-private partnerships. Built Environment Project and Asset Management, 8(5), 449-460. doi:10.1108/bepam-102017-0087

Dolla, T., \& Laishram, B. (2020). Factors affecting public-private partnership preference in Indian municipal waste sector. International Journal of Construction Management, 20(6), 567-584. doi:10.1080/15623599.2019.1703085

Eadie, R., Millar, P., \& Grant, R. (2013). PFI/PPP, private sector perspectives of UK transport and healthcare. Built Environment Project and Asset Management, 3(1), 89-104. doi:10.1108/bepam-02-2012-0005

Eaton, D., Akbiyikli, R., \& Dickinson, M. (2006). An evaluation of the stimulants and impediments to innovation within PFI/PPP projects. Construction Innovation, 6(2), 63-67. doi:10.1108/14714170610710668 
Ferguson, G. A., \& Takane, Y. (1989). Regression and Correlations. Statistical Analysis in Psychology and Education (6th ed., pp. 133-382). New York: McGraw-Hill.

Flyvbjerg, B., Skamris Holm, M. K., \& Buhl, S. L. (2004). What Causes Cost Overrun in Transport Infrastructure Projects? Transport Reviews, 24(1), 3-18. doi:10.1080/0144164032000080494a

Fourie, F. C., \& Burger, P. (2000). An Economic Analysis and Assessment of Public - Private Partnerships (PPPs). The South African Journal of Economics, 68(4), 305-316. doi:10.1111/j.1813-6982.2000.tb01274.x

Gunjeet, K., Sanjib, B., \& Raj, R. (2009). An Empirical Investigation of the Inter-Sectoral Linkages in India. Reserve Bank of India Occasional Papers, 30(1), 29-72.

Hans, A. 2017. Rebooting Public Private Partnership in India. Accessed 30 November 2018. http://niti.gov.in/content/rebooting-public-private-partnership-india

Henjewele, C., Sun, M., \& Fewings, P. (2014). Comparative performance of healthcare and transport PFI projects: Empirical study on the influence of key factors. International Journal of Project Management, 32(1), 77-87. doi:10.1016/j.ijproman.2013.01.008

HMT. (2012). A new approach to public private partnerships. London: HM Treasury.

Hodge, G., \& Greve, C. (2010). Public-Private Partnerships: Governance Scheme or Language Game? Australian Journal of Public Administration, 69, S8-S22. doi:10.1111/j.1467-8500.2009.00659.x

Hwang, B G., Zhao X. \& Gay M. J. S. (2013). Public private partnership projects in Singapore: Factors, critical risks and preferred risk allocation from the perspective of contractors. International Journal of Project Management, 31(2013), 424-433. http://dx.doi.org/10.1016/j.ijproman.2012.08.003

Kirkpatrick, L. A., \& Feeney, B. C., (2001). A Simple Guide to SPSS for Windows: Versions 8.0,9.0 and 10.0.(4 ${ }^{\text {th }}$ ed.) Belmont, California: Wadsworth Publishing.

Klijn, E., \& Teisman G. (2000). Governing public-private partnerships: analysing and managing the processes and institutional characteristics of public-private partnerships. In: Stephen P. Osborne, editor. Public-private partnerships theory and practice in international perspective. pp. 84-102. London: Routledge.

Levin, R. I., Rubin, D. S., Rastogi, S., \& Siddiqui, M. H., (2013). Statistics for Management (7 ${ }^{\text {th }}$ ed.). India: Dorling Kindersley (India) Pvt. Ltd., licensees of Pearson Education in South Asia.

Li, B., Akintoye, A., Edwards, P. J., \& Hardcastle, C. (2005a). The allocation of risk in PPP/PFI construction projects in the UK. International Journal of Project Management, 23(1), 25-35. doi:10.1016/j.ijproman.2004.04.006

Li, B., Akintoye, A., Edwards, P. J., \& Hardcastle, C. (2005b). Critical success factors for PPP/PFI projects in the UK construction industry. Construction Management and Economics, 23(5), 459-471. doi:10.1080/01446190500041537

Li, B., Akintoye, A., Edwards, P. J., \& Hardcastle, C. (2005c). Perceptions of positive and negative factors influencing the attractiveness of PPP/PFI procurement for construction projects in the UK - Findings from a questionnaire survey. Engineering, Construction and Architectural Management, 12(2), 125-148. doi:10.1108/09699980510584485

Malek, S., \& Akalkotkar, P. (2016). Factors contributing to successful Public Private Partnership Projects for Highway Projects in Indian Context. International Journal for Scientific Research and Development 3(12), $25-29$.

Malek, M., Bhatt, V., \& Patel, A. (2020). Global national and local growth of road projects through PPP. TEST Engineering and Management March-April (2020) 25837-25860.

Malek M., \& Gundaliya P. (2020). Value for money factors in Indian public-private partnership road projects: an exploratory approach. Journal of Project Management, 6(1), 23-32. doi:10.5267/j.jpm.2020.10.002.

Malek M., \& Gundaliya P. (2020a). Negative factors in implementing public-private partnership in Indian road projects, International Journal of Construction Management, doi: 10.1080/15623599.2020.1857672

Malek, M., Mohibali, S \& Bachwani, D. (2021). Identification, evaluation, and allotment of critical risk factors (CRFs) in real estate projects: India as a case study. Journal of Project Management, 6(2), 83-92. doi:10.5267/j.jpm.2021.1.002

Mendenhall, W. (1971). Introduction to Probability and Statistics. ( $3^{\text {rd }}$ ed.) Belmont, California: Duxbury Press.

Rajan, T. A., Gopinath, G., \& Behera, M. (2014). PPPs and Project Overruns: Evidence from Road Projects in India. Journal of Construction Engineering and Management, 140(5), 04013070. doi:10.1061/(asce)co.1943-7862.0000797

Robert, O. K., Dansoh, A., \& Ofori - Kuragu, J. K. (2014). Reasons for adopting Public-Private Partnership (PPP) for construction projects in Ghana. International Journal of Construction Management, 14(4), $227-238$. doi:10.1080/15623599.2014.967925

Thillai Rajan, A., \& Deep, A. (2019) Sep. More highways should be built by States. Bus Line. http://thehindubusinessline.com/opinion/more-highways-should-be-built-by-states/article29401496.ece.

World Bank Group. (2016). The state of PPPs: infrastructure public- private partnerships in emerging markets and developing economies 1991-2015. Washington, D.C: The World Bank and PPIAF.

Zhang, X. Q., \& Kumaraswamy, M. M. (2001). Procurement Protocols for Public-Private Partnered Projects. Journal of Construction Engineering and Management, 127(5), 351-358. doi:10.1061/(asce)0733-9364(2001)127:5(351)

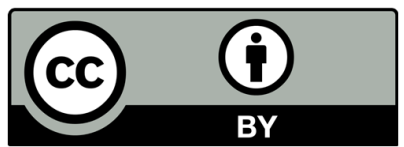

(C) 2022 by the authors; licensee Growing Science, Canada. This is an open access article distributed under the terms and conditions of the Creative Commons Attribution (CC-BY) license (http://creativecommons.org/licenses/by/4.0/). 